\title{
A PRESENÇA DO SAGRADO EM DUAS TRADUÇÕES DO CONTO "THE HAMMER OF GOD", DE GILBERT K. CHESTERTON: UMA ANÁLISE À LUZ DA LINGUÍSTICA DE CORPUS
}

\author{
Aline Milani Romeiro Pereira ${ }^{1}$ \\ Diva Cardoso de Camargo 1 \\ -1Universidade de São Paulo, São Paulo, São Paulo, Brasil
}

\begin{abstract}
Resumo: Este estudo apresenta uma análise de duas traduções para o português brasileiro do conto "The Hammer of God", da coletânea The Innocence of Father Brown, de Gilbert K. Chesterton, publicada pela primeira vez em 1911, sendo o primeiro dos cinco volumes sobre o padre-detetive. As traduções selecionadas para este estudo, foram: "O Martelo de Deus", de Carlos Nougué (2006) e “A Marreta de Deus”, do grupo de tradução de Beatriz Viégas-Faria (2011). A partir do arcabouço teórico dos Estudos da Tradução Baseados em Corpus (ETBC) (Baker, 1995, 1996, 2000; Camargo, 2007) observamos o que diferencia os textos em termos de apropriação do universo religioso habitado por Father Brown, personagem principal da série. Para efetuar as análises utilizou-se o programa WordSmith Tools, em especial as ferramentas WordList, Concord e Aligner, adotadas para a verificação das opções tradutórias dadas aos vocábulos pertencentes ao campo semântico da religião. Os resultados sugerem a valorização do aspecto religioso em ambas as traduções, em termos de frequência e variedade, a despeito das diferenças entre as escolhas tradutórias em cada caso. O estudo do corpus evidencia que o caráter investigado está mais presente em "A Marreta de Deus".
\end{abstract}

Palavras-Chave: Father Brown; Religião; ETBC 


\title{
SACREDNESS PRESENTED IN TWO TRANSLATIONS OF GILBERT K. CHESTERTON'S SHORT STORY “THE HAMMER OF GOD": A CORPUS-BASED ANALYSIS
}

\begin{abstract}
This study presents an analysis of two translations into Brazilian Portuguese of the short-story "The Hammer of God", first published in 1911 as part of Gilbert K. Chesterton's The Innocence of Father Brown. The translations selected were "O Martelo de Deus", by Carlos Nougué (2006) and “A Marreta de Deus”, by Beatriz Viégas-Faria's translation group (2011). From the theoretical perspective of CorpusBased Translation Studies (Baker, 1995, 1996, 2000; Camargo, 2007), we intend to observe existing differences between the translations and the original text regarding characteristics of the religious universe of the priest-detective, the main character of the series. To conduct the analyses, we have made use of the software WordSmith Tools, mainly of the tools WordList, Concord and Aligner, in order to observe the choices made in the translation of words from the semantic field of religion. The results point to an increased focus on the religious aspect in both translations, at times even surpassing the original work in terms of the occurrence of related vocabulary, especially in the case of "A Marreta de Deus".
\end{abstract}

Key words: Father Brown; Religion; Corpus-Based Translation Studies

\section{Introdução}

É ambígua a posição de um tradutor literário diante de um texto. Muitos consideram que realiza uma reescritura do material em suas mãos, mas não é autor. Apesar de sua leitura certamente cuidadosa e atenta, tampouco é leitor. Pode-se dizer que tal profissional estabelece em sua prática cotidiana um diálogo com esses dois interlocutores: o autor e o leitor, sempre por meio da palavra escrita e com a mediação de fatores diversos. Sua atuação não se conclui ao final da tarefa de tradução propriamente dita, mas ali tem seu início.

Dada esta dinâmica única entre autor-tradutor-leitor, traduções diferentes feitas a partir de um mesmo original constituem, em si mesmas, exemplos de uma multiplicidade de leituras possíveis. 
Resultam de abordagens distintas do texto original, que podem ser exemplificadas ao considerarmos as diferentes nuances transmitidas por cada palavra escolhida para fazer parte - ou estar ausente - de uma tradução. Assim, como leitor privilegiado, cada tradutor tem a responsabilidade de conduzir os demais leitores por caminhos alicerçados nas escolhas e soluções adotadas no texto.

A singularidade da relação acima descrita impulsiona a constante realização de trabalhos comparativos entre textos e respectivas traduções, tal como proposto neste artigo. Dentre as muitas opções disponíveis no universo literário, optamos por abordar uma obra cujo personagem principal carrega a ambiguidade em si: $F a$ ther Brown, o padre-detetive criado pelo escritor inglês Gilbert K. Chesterton. Com amparo nos conceitos dos Estudos da Tradução Baseados em Corpus (Baker, A, B, C; Camargo), tratamos, aqui, das diferenças quanto à tradução dos vocábulos relacionados ao campo semântico da religião em um conto que tem o referido personagem como protagonista.

Tendo como foco este aspecto bastante específico - o sagrado escolhemos fazer um contraponto entre o conto "The Hammer of God" (1911) e duas de suas traduções mais recentes: “O Martelo de Deus", de Carlos Nougué (2006), lançado pela editora Sétimo Selo, e "A Marreta de Deus", do grupo de tradução de Beatriz Viégas-Faria (2011), publicado pela LPM. O conto, que evoca em seu próprio título a presença do universo religioso, faz parte da coletânea The Innocence of Father Brown (A Inocência do Padre Brown), livro inaugural da série sobre o padre-detetive. Embora nem toda a literatura de Gilbert K. Chesterton esteja traduzida para o português, seja brasileiro ou europeu, a saga do sacerdote apresenta diversas versões em nosso idioma, lançadas a partir dos anos 30, sendo The Innocence of Father Brown a publicação que dispõe de mais traduções atualmente em catálogo no Brasil. 


\section{Autor e obra}

A literatura policial é, por vezes, relegada a um plano secundário e considerada de menor qualidade quando comparada às obras reconhecidamente canônicas. A despeito de sua posição nem sempre privilegiada na academia, este tipo de literatura tem encontrado seguidores fiéis entre o público leitor, o que contribui para que permaneça como gênero amplamente consumido e revisitado. A fama de certos personagens oriundos desse gênero ultrapassa inclusive o universo literário, estando, dentre os mais célebres, os detetives Hercule Poirot, de Agatha Christie, e Sherlock Holmes, de Sir Arthur Conan Doyle, cujas aventuras figuram no imaginário coletivo e há décadas instigam os leitores.

De maneira análoga, a literatura de caráter religioso - ou mesmo sobrenatural - também se apresenta como um segmento de sucesso, constando em listas de obras regularmente consumidas por um público que a mantém sempre no foco do interesse, a despeito de sua parcial aceitação como representante tradicional do fazer literário. No Brasil, por exemplo, livros escritos por representantes religiosos de renome servem para alavancar as vendas em épocas de crise, trazendo certa visibilidade às doutrinas pregadas, mesmo que isso nem sempre signifique maior adesão oficial a uma ou outra religião.

Uma aproximação entre esses dois universos - policial e religioso - pode parecer improvável, e seu sucesso, mais ainda, porém a historiografia da literatura policial nos prova o contrário. Um de seus personagens mais famosos é um detetive cujo sucesso como investigador está diretamente relacionado à sua vivência no campo religioso: Padre Brown, criado pelo escritor britânico Gilbert K. Chesterton no início do século XX.

Gilbert K. Chesterton nasceu em Londres em 1874 e faleceu em 1936. Durante sua vida profissional exerceu diversas atividades, a maioria delas relacionada à palavra escrita. Em sua prolífica carreira atuou como escritor, poeta, narrador, ensaísta, jornalista, historiador, biógrafo, teólogo, filósofo, desenhista e conferencista.

Cad. Trad., Florianópolis, v. 39, no 3, p. 230-248, set-dez, 2019. 
Escreveu cerca de oitenta livros, entre os mais famosos, Ortodoxia, obra em que defende os valores do catolicismo, religião à qual se converteu em 1922. Em seus escritos, Chesterton abordava de forma crítica uma gama variada de assuntos, desde filosofia até economia, e por essa razão costumava travar debates intelectuais com importantes contemporâneos, entre eles os escritores Bernard Shaw e H.G Wells, e o filósofo Bertrand Russel.

Seu trabalho de ficção mais conhecido trata das experiências de um homem dotado de grande talento investigativo, o sacerdote católico Padre Brown, personagem que estrela a coleção de contos composta pelos seguintes volumes: The Innocence of Father Brown (1911), The Wisdom of Father Brown (1914), The Incredulity of Father Brown (1926), The Secret of Father Brown (1927), The Scandal of Father Brown (1935).

Como explicitado nos títulos acima, o personagem principal é um padre capaz de solucionar os mais misteriosos e violentos crimes, sempre fazendo uso de seu conhecimento do mundo a partir de experiências vividas na igreja, entre os fiéis, e principalmente, entre os "infiéis". Foi inspirado em uma figura real, o sacerdote John O’Connor (1870-1952), amigo de Chesterton. A partir da mistura de dois mundos aparentemente distantes, o autor foi capaz de perpetuar a figura desse personagem inusitado que figura ainda hoje em diversas adaptações. Propor razões que expliquem como esse personagem do início do século sobreviveu até hoje seria material para outro estudo, mas é possível apontar para um possível caminho, considerando as temáticas tratadas por Chesterton:

A partir das temáticas sociais e teológicas dos contos do Padre Brown, o leitor pode notar que as obras chestertonianas do gênero policial não abarcam somente o entretenimento, mas conceitos universais, discutidos de gerações em gerações, tais como sofrimento humano, pecado e arrependimento. (Garcia 63) 
Como exemplo de algumas versões famosas de suas aventuras podemos citar o filme The Detective, de 1954, estrelado pelo ator Alec Guinness; uma série para a rádio BBC produzida entre 1984 e 1986; e o seriado Father Brown, exibido pelo canal televisivo inglês BBC desde 2013, atualmente em sua sexta temporada.

Sejam quais forem as razões, Padre Brown ainda conquista novos fãs, garantindo seu lugar entre os detetives mais famosos da literatura, e aparece agora mais uma vez em destaque, na presente investigação acadêmica, realizada à luz dos Estudos da Tradução Baseados em Corpus.

\section{Fundamentação teórica}

Adotamos como arcabouço teórico-metodológico desta pesquisa os Estudos da Tradução Baseados em Corpus (Baker, A, B, C; Camargo, 2007). Os fundamentos dos ETBC vão ao encontro das necessidades e possibilidades identificadas no campo dos Estudos Descritivos da Tradução, sendo possível, com sua aplicação, avançar significativamente em direção a uma análise de textos traduzidos em contextos reais.

Baker (A) apresenta a análise de corpora por meios eletrônicos como um maneira de perceber diferenças entre a linguagem específica da tradução e a dos textos originalmente escritos em determinada língua, partindo da definição de corpus, também adotada na presente pesquisa, como "um conjunto de textos naturais (e não de exemplos ou sentenças), em formato eletrônico, passíveis de análise, preferencialmente, de forma automática ou semi-automática (e não manualmente)". (Baker 226, tradução nossa ${ }^{1}$ ).

O desenvolvimento dos conceitos trazidos por Baker com os ETBC relaciona-se diretamente com o advento do uso de ferra-

\footnotetext{
1 "any collection of running texts (as opposed to examples/sentences), held in electronic form and analyzable automatically or semi-automatically (rather than manually)." (tradução nossa)
}

Cad. Trad., Florianópolis, v. 39, no 3, p. 230-248, set-dez, 2019. 
mentas computacionais para a análise de textos. É sabido que a realização de um estudo à luz da linguística de corpus pressupõe a escolha de um programa ou ferramenta computacional para o processamento das informações, porque "possibilitam a remodelagem de um conjunto de dados em uma nova forma a fim de se identificar padrões" (Kader and Richter 14). Uma das ferramentas mais difundidas entre as atualmente disponíveis no mercado, e cujo desempenho tem sido elogiado por pesquisadores da área é o conjunto de programas integrados WordSmith Tools. Segundo afirma Berber Sardinha (2009), sua popularidade baseia-se em alguns aspectos: ser escrito para o ambiente Windows, ou seja, de interface já conhecida, ser também de simples utilização e fácil aquisição. Por essa razão foi a ferramenta adotada para este estudo, tendo sido utilizados, em especial, os seguintes recursos:

- WordList - fornece listas de palavras, que podem ser exibidas por ordem de frequência ou alfabética, e também traz dados estatísticos dos textos selecionados.

- Concord - apresenta listas de agrupamentos lexicais e colocados a partir de palavras inseridas no campo de busca, além de localizar no corpus a palavra selecionada.

- Aligner - alinha os períodos para que se possa visualizar, par a par, os textos original e traduzido.

Os resultados obtidos são interpretados considerando-se os valores das estatísticas fornecidos pelo programa. Consideramos como ponto de partida para esta pesquisa as informações de cunho mais genérico relacionadas aos conceitos abaixo, e geradas pelas WordList:

- Número de itens (ou tokens): total de palavras ou ocorrências

- Número de formas (ou types): total de palavras distintas

- Razão forma/item (ou type/token ratio): valor expresso em porcentagem, obtido pela divisão do total de formas pelo to- 
tal de itens. Indica a riqueza lexical do texto, ou seja, quanto maior a razão forma/item, maior o número de ocorrência de palavras diferentes.

- Razão forma/item padronizada (ou standardized type/token ratio): valor médio calculado de acordo com intervalos regulares de texto. É adotada quando os textos de um corpus possuem tamanhos diferentes.

É pertinente ressaltar que, embora gere uma ampla gama de resultados, o WordSmith Tools é tão somente um recurso, uma vez que "disponibiliza uma série de opções de ferramentas (daí o 'tools' em seu nome), algumas mais gerais, outras mais restritas, sem jamais supor que a análise termine com o processamento de dados que ele efetua" (Berber Sardinha 5).

Embora possa ser mais imediato pensar a aplicação dos ETBC para textos de especialidade, pela própria natureza destes, a abordagem de traduções literárias à luz da linguística de corpus também tem sido uma área de estudos em expansão, com significativa produção acadêmica em nosso país e no exterior.

Alguns exemplos de tal aplicação podem ser vistos no estudo de Zyngier et al. (2011), em os autores apresentam um panorama bastante rico sobre estudos de corpora literários realizados por diversos pesquisadores em literatura. Muitos dos resultados obtidos nessas pesquisas contrariam noções pré-estabelecidas pela crítica a respeito de algumas das obras tratadas, comprovando que a linguística de corpus pode

fornecer ao crítico literário as ferramentas e os princípios necessários para que a literatura seja analisada sob uma nova perspectiva, mais objetiva do que a que tradicionalmente caracteriza a análise de base hermenêutica. (Zyngier et al. 102).

É com base nesses diversos estudos prévios bem-sucedidos que escolhemos propor uma análise de aspectos específicos presentes 
na tradução de uma reduzida amostra da literatura de Gilbert K. Chesterton. Dada a conceituação de corpus como "uma coletânea de textos em formato eletrônico, compilada segundo critérios específicos, considerada representativa de uma língua (ou da parte que se pretende estudar), destinada à pesquisa" (Tagnin 4), podemos considerar adequação essa abordagem para o material e o propósito escolhidos.

O emprego de corpora paralelos, em que textos traduzidos são examinados lado a lado com os respectivos textos de partida, permite a comparação entre original e traduções, e, por extensão, entre os próprios textos traduzidos, ou seja, "possibilita, mais objetivamente, a identificação de padrões e estilos individuais, distintivos, preferenciais e recorrentes dos tradutores literários em relação ao estilo do autor" (Camargo 48).

Segundo nos aponta Baker (2000), a noção de estilo do tradutor literário contraria a ideia de que o tradutor não possuiria uma "voz" própria, sendo apenas um reprodutor - quanto mais fiel possível - do estilo de determinado autor. A presente pesquisa baseia-se, portanto, nesse "olhar individual para o tradutor", uma vez que, a partir das convergências e divergências identificadas neste estudo, poderemos ser capazes de descrever aspectos únicos e particulares de cada tradução estudada, e, consequentemente, identificar características específicas de quem as concebeu.

\section{Metodologia}

Para a compilação do corpus a ser analisado, os três textos foram escaneados a partir das respectivas edições impressas e todo o material foi convertido para o formato $t x t$, por meio da ferramenta Online OCR. Após esta etapa foi necessária também uma correção manual dos textos.

Obtidas as versões finais do original e das traduções, empregou-se o programa WordSmith Tools, versão 7.0. Primeiramente utilizamos a ferramenta WordList para obter a lista de palavras, em 
ordem decrescente de frequência, para cada texto. Das listas iniciais obteve-se uma nova lista constando apenas dos substantivos, foco principal de nossa análise e caracterizados por sua maior relevância para a investigação do aspecto tratado na pesquisa. A partir dos substantivos, foram, então, selecionados aqueles passíveis de pertencerem ao campo semântico da religião.

Em seguida, utilizou-se a ferramenta Concord - que apresenta os vocábulos em contexto - para esclarecer dúvidas quanto à pertinência de cada uma das palavras inicialmente selecionadas ao contexto desejado. Tal análise revelou, por exemplo, que 'irmão' e 'senhor', embora passíveis de pertencerem ao campo semântico da religião, não haviam sido utilizadas com tal conotação no contexto do conto.

Para melhor observar as correspondências entre o texto em inglês e seus pares em português, utilizamos a ferramenta Aligner, que possibilitou identificar as soluções tradutórias adotadas em cada situação. Uma vez que este trabalho objetiva a comparação entre duas traduções, foram desconsiderados os casos em que houve coincidência nas escolhas tradutórias. Desse modo, a lista resultante, na qual baseiamse nossos comentários, é composta de 12 palavras que ilustram a diversidade de soluções adotadas, conforme mostrado a seguir.

\section{Análise dos Resultados}

A análise dos resultados genéricos obtidos pela ferramenta WordList evidencia ao menos uma importante semelhança em relação à razão forma/item dos textos traduzidos, como pode ser visto na tabela a seguir:

Tabela 5.1 - Razão forma-item e razão forma-item padronizada do texto original e respectivas traduções

\begin{tabular}{l|l|l|l}
\hline TEXTO & $\begin{array}{l}\text { The Hammer } \\
\text { of God }\end{array}$ & $\begin{array}{l}\text { A Marreta } \\
\text { de Deus }\end{array}$ & $\begin{array}{l}\text { O Martelo } \\
\text { de Deus }\end{array}$ \\
\hline RAZÃO FORMA/ITEM & 23,98 & 30,33 & 29,70 \\
\hline
\end{tabular}

Cad. Trad., Florianópolis, v. 39, no 3, p. 230-248, set-dez, 2019. 


\begin{tabular}{l|l|l|l}
\hline $\begin{array}{l}\text { RAZÃO FORMA/ITEM } \\
\text { PADRONIZADA }\end{array}$ & 42,75 & 48,52 & 46,88 \\
\hline
\end{tabular}

Fonte: Elaborada pelas autoras

Ao contrário do que é comumente observado em textos traduzidos, a razão forma/item, indicativa da riqueza vocabular, é maior no caso das traduções. Considerando-se que G. K. Chesterton é conhecido por uma escrita peculiar caracterizada pelo constante uso de analogias e paradoxos, os resultados podem refletir uma maior necessidade de explicações para esclarecer ou explicitar elementos da narrativa em língua portuguesa. A maior variedade vocabular também é evidenciada na lista a seguir, que apresenta os substantivos selecionados e as respectivas traduções, considerando-se as palavras mais frequentes do texto original.

Tabela 5.2 - Substantivos pertencentes ao campo semântico da religião e respectivas frequências nos textos original e traduzidos

\begin{tabular}{|c|c|c|c|c|c|}
\hline $\begin{array}{l}\text { The Hammer } \\
\text { of God }\end{array}$ & Freq. & $\begin{array}{l}\text { A Marreta de } \\
\text { Deus }\end{array}$ & Freq. & $\begin{array}{l}\text { O Martelo de } \\
\text { Deus }\end{array}$ & Freq. \\
\hline PRIEST & 17 & $\begin{array}{l}\text { PADRE } \\
\text { SACERDOTE }\end{array}$ & $\begin{array}{l}14 \\
3\end{array}$ & $\begin{array}{l}\text { PADRE } \\
\text { PADRECO }\end{array}$ & $\begin{array}{l}12 \\
5\end{array}$ \\
\hline GOD & 10 & $\begin{array}{l}\text { DEUS, } \\
\text { DIVINO }\end{array}$ & $\begin{array}{l}9 \\
1\end{array}$ & DEUS & 10 \\
\hline CURATE & 9 & VIGÁRIO & 9 & $\begin{array}{l}\text { PADRE } \\
\text { CURA }\end{array}$ & $\begin{array}{l}1 \\
8\end{array}$ \\
\hline PRAYERS & 4 & $\begin{array}{l}\text { PRECES } \\
\text { SÚPLICAS } \\
\end{array}$ & $\begin{array}{l}3 \\
1 \\
\end{array}$ & ORAÇÕES & 4 \\
\hline PRAYER & 2 & $\begin{array}{l}\text { ORAÇÃO } \\
\text { DEVOÇÃO } \\
\end{array}$ & $\begin{array}{l}1 \\
1 \\
\end{array}$ & ORAÇÃO & 2 \\
\hline CHAPEL & 2 & CAPELA & 2 & $\begin{array}{l}\text { IGREJA } \\
\text { TEMPLO }\end{array}$ & $\begin{array}{l}1 \\
1\end{array}$ \\
\hline
\end{tabular}

Cad. Trad., Florianópolis, v. 39, no 3, p. 230-248, set-dez, 2019. 


\begin{tabular}{l|l|l|l|l|l}
\hline SPIRE & 2 & $\begin{array}{l}\text { PINÁCULO } \\
\text { TORRE DA } \\
\text { IGREJA }\end{array}$ & 1 & $\begin{array}{l}\text { AGULHA } \\
\text { PINÁCULO }\end{array}$ & 1 \\
\hline CLERGYMEN & 1 & CLÉRIGOS & 1 & PADRES & 1 \\
\hline INFIDELS & 1 & ÍMPIOS & 1 & INFIÉIS & 1 \\
\hline HEATHEN & 1 & ATEU & 1 & HEREGE & 1 \\
\hline HEAVEN & 1 & PARAÍSO & 1 & CÉU & 1 \\
\hline WORSHIPPER & 1 & DEVOTO & 1 & FIEL & 1 \\
\hline
\end{tabular}

Fonte: Elaborada pelas autoras

A análise dos dados acima confirma o que já havia sido apontado pelos resultados numéricos da tabela 4.1. Observa-se uma maior apropriação do universo religioso pelos tradutores, uma vez que os 12 substantivos analisados resultaram em um total de 17 ocorrências diferentes em $A$ Marreta de Deus, e de 16 em $O$ Martelo de Deus. A tabela acima nos mostra que, dentre as duas traduções, $A$ Marreta de Deus é a que apresenta maior número de ocorrências distintas e também mais especificidade no uso do vocabulário religioso, ou seja, é a tradução que possui maior riqueza vocabular, a partir de uma perspectiva quantitativa e qualitativa.

A seguir apresentamos considerações acerca de algumas das escolhas tradutórias feitas, ressaltando aspectos que as diferenciam entre si e em relação ao texto original em inglês.

\section{Priest}

Em “A Marreta de Deus" as opções adotadas foram 'padre' e 'sacerdote', sendo a segunda opção, nos três casos, uma referência ao Padre Wilfred Bohun, representante da paróquia onde se passa a narrativa. No caso de "O Martelo de Deus", destaca-se o uso da palavra 'padreco', utilizada sempre com referência ao Padre Brown: 
Quadro 5.1 - Exemplos de traduções para o vocábulo 'priest'

\begin{tabular}{|c|c|c|}
\hline The Hammer of God & A Marreta de Deus & O Martelo de Deus \\
\hline $\begin{array}{l}\text {... said a small and } \\
\text { colourless voice, which } \\
\text { came from the little }\end{array}$ & $\begin{array}{l}\text {... disse uma vozinha } \\
\text { sem graça, a voz do } \\
\text { pequenino }\end{array}$ & $\begin{array}{l}\text {...disse uma vozinha } \\
\text { apagada, que vinha do }\end{array}$ \\
\hline $\begin{array}{l}\text { Roman priest who had } \\
\text { joined the group. }\end{array}$ & $\begin{array}{l}\text { padre católico que se } \\
\text { juntara ao grupo. }\end{array}$ & $\begin{array}{l}\text { padreco católico que } \\
\text { se tinha juntado ao } \\
\text { grupo. }\end{array}$ \\
\hline $\begin{array}{l}\text { The little priest was not } \\
\text { an interesting man to } \\
\text { look at. }\end{array}$ & $\begin{array}{l}\text { O pequenino padre } \\
\text { não era interessante } \\
\text { de se contemplar. }\end{array}$ & $\begin{array}{l}\text { O padreco não } \\
\text { era um homem } \\
\text { interessante de olhar. }\end{array}$ \\
\hline $\begin{array}{l}\text { All glanced round and } \\
\text { the short priest went } \\
\text { across... }\end{array}$ & $\begin{array}{l}\text { Todos correram os } \\
\text { olhares ao redor; } \\
\text { o pequenino padre } \\
\text { aproximou-se... }\end{array}$ & $\begin{array}{l}\text { Olharam todos para } \\
\text { onde ele apontara, e o } \\
\text { padreco foi até... }\end{array}$ \\
\hline $\begin{array}{l}\text {... as did everybody } \\
\text { else, except the short, } \\
\text { strange priest... }\end{array}$ & $\begin{array}{l}\text {...como fizeram os } \\
\text { outros presentes, } \\
\text { exceto o estranho e } \\
\text { pequenino padre... }\end{array}$ & $\begin{array}{l}\text {...como fizeram todos } \\
\text { os outros, menos o } \\
\text { padreco forasteiro... }\end{array}$ \\
\hline $\begin{array}{l}\text { 'Come up here, Mr. } \\
\text { Bohun,' he called. ' }\end{array}$ & $\begin{array}{l}\text { - Suba aqui, sr. } \\
\text { Bohun - chamou ele. }\end{array}$ & $\begin{array}{l}\text { - Venha cá para cima, } \\
\text { Mr. Bohun - chamou } \\
\text { o padreco. }\end{array}$ \\
\hline
\end{tabular}

Fonte: Elaborado pelas autoras

Embora possa ser utilizada para designar um padre de baixa estatura, a palavra 'padreco' é mais comumente empregada como sinônimo de um padre extremamente jovem ou de pouco valor, o que não se infere a partir do texto original. Em "A Marreta de Deus", ao contrário, as menções ao jeito peculiar do Padre Brown não são ressaltadas, mas atenuadas por meio do adjetivo 'pequenino'. No texto original, Chesterton adota a expressão 'little priest', que parece referir-se apenas à estatura do padre em questão, sem conferir juízo de valor acerca de sua pessoa ou prática sacerdotal. 


\section{Curate}

No caso de 'curate' ambas os textos traduzidos apresentam opções bastante específicas do contexto religioso. Foram adotados os sinônimos 'cura', em "O Martelo de Deus' e 'vigário', em “A Marreta de Deus".

\section{Prayer/prayers}

O par 'prayer/prayers' também ilustra diferenças significativas entre os dois textos traduzidos.

Quadro 5.2 - Exemplos de traduções para os vocábulos 'prayer/ prayers'

\begin{tabular}{|l|l|l|}
\hline The Hammer of God & A Marreta de Deus & O Martelo de Deus \\
\hline $\begin{array}{l}\text {... Wilfred Bohun } \\
\text { was very devout, } \\
\text { and was making his } \\
\text { way to some austere } \\
\text { exercises of prayer } \\
\text { or contemplation at } \\
\text { dawn. }\end{array}$ & $\begin{array}{l}\text {..Wilfred Bohun } \\
\text { era muito devoto e } \\
\text { estava a caminho } \\
\text { das suas austeras } \\
\text { práticas de oração } \\
\text { ou contemplação ao } \\
\text { amanhecer. }\end{array}$ & $\begin{array}{l}\text { Wilfred Bohun era } \\
\text { muito piedoso, e } \\
\text { estava dirigirindo- } \\
\text { se aos austeros } \\
\text { exercícios de oração } \\
\text { e contemplação, } \\
\text { que cumpria ao } \\
\text { amanhecer. }\end{array}$ \\
\hline $\begin{array}{l}\text { Indeed, the } \\
\text { charge was mostly } \\
\text { an ignorant } \\
\text { misunderstanding of } \\
\text { the love of solitude } \\
\text { and secret prayer... }\end{array}$ & $\begin{array}{l}\text { Na verdade, a } \\
\text { acusação era, em } \\
\text { grande parte, uma } \\
\text { interpretação errônea } \\
\text { do seu amor à } \\
\text { solidão e à devoção } \\
\text { reservada... }\end{array}$ & $\begin{array}{l}\text { De fato, tal } \\
\text { insinuação era em } \\
\text { grande parte um mal- } \\
\text { entendido quanto ao } \\
\text { amor e a solidão e da } \\
\text { oração solitária... }\end{array}$ \\
\hline $\begin{array}{l}\text { What sort of prayers } \\
\text { was he saying now? } \\
\text { Extraordinary prayers } \\
\text { surely. }\end{array}$ & $\begin{array}{l}\text { Que tipo de preces } \\
\text { ele estava fazendo } \\
\text { agora? Preces } \\
\text { extraordinárias, com } \\
\text { certeza. }\end{array}$ & $\begin{array}{l}\text { Que espécie de } \\
\text { orações estaria } \\
\text { rezando agora? } \\
\text { Por certo, orações } \\
\text { extraordinárias. }\end{array}$ \\
\hline \multicolumn{2}{|l|}{}
\end{tabular}

Cad. Trad., Florianópolis, v. 39, no 3, p. 230-248, set-dez, 2019. 


\begin{tabular}{|c|c|c|}
\hline $\begin{array}{l}\text { This ugly sunlit picture } \\
\text { of the stupidity and } \\
\text { cruelty of the earth } \\
\text { sent the ascetic finally } \\
\text { to his prayers for } \\
\text { purification and new } \\
\text { thoughts. }\end{array}$ & $\begin{array}{l}\text { Essa horrenda } \\
\text { imagem luminosa } \\
\text { da estupidez e da } \\
\text { crueldade terrenas } \\
\text { enviou o asceta } \\
\text { por fim para as } \\
\text { suas súplicas por } \\
\text { purificação e novos } \\
\text { pensamentos. }\end{array}$ & $\begin{array}{l}\text { Esta feia cena, à luz } \\
\text { do sol, da estupidez e } \\
\text { crueldade do mundo, } \\
\text { levou por fim o asceta } \\
\text { a suas orações para } \\
\text { purificar-se, e pensar } \\
\text { em outras coisas. }\end{array}$ \\
\hline
\end{tabular}

Fonte: Elaborado pelas autoras

Mais uma vez, "A Marreta de Deus” apresenta maior pluralidade de escolhas que conferem nuances ao texto, como, por exemplo, 'súplicas'. Neste caso, ressalta-se o estado de espírito do homem que não reza, somente, mas implora por algo a Deus. Em "O Martelo de Deus", ao contrário, temos somente a tradução literal do par prayer/prayers.

\section{Infidels/worshipper}

Um paralelo similar ao descrito anteriormente é observado nas traduções de 'infidels' e 'worshipper'. Novamente, “A Marreta de Deus" traz à cena o vocabulário peculiar da religião católica e do contexto religioso/bíblico, 'devoto' e 'ímpios', respectivamente.

Quadro 5.3 - Exemplos de traduções para os vocábulos 'infidels/ worshippers'

\begin{tabular}{|c|c|c|}
\hline The Hammer of God & A Marreta de Deus & O Martelo de Deus \\
\hline $\begin{array}{l}\text { It's well for you } \\
\text { infidels to dodge like } \\
\text { foxes because the } \\
\text { world's law favours } \\
\text { you. }\end{array}$ & $\begin{array}{l}\text { É bem cômodo para } \\
\text { vocês, não é, seu } \\
\text { bando de ímpios, } \\
\text { ficar se esquivando } \\
\text { feito raposas, só } \\
\text { porque a lei do } \\
\text { mundo os favorece. }\end{array}$ & $\begin{array}{l}\text { Está certo que vocês, } \\
\text { infiéis, enganem } \\
\text { como raposas, porque } \\
\text { as leis do mundo estão } \\
\text { a seu favor. }\end{array}$ \\
\hline
\end{tabular}

Cad. Trad., Florianópolis, v. 39, no 3, p. 230-248, set-dez, 2019. 


\begin{tabular}{|l|l|l|}
\hline $\begin{array}{l}\text { For the early } \\
\text { worshipper was none } \\
\text { other than the village } \\
\text { idiot, } \text { a nephew of the } \\
\text { blacksmith... }\end{array}$ & $\begin{array}{l}\text { Porque o matinal } \\
\text { devoto não poderia } \\
\text { ser outra pessoa } \\
\text { senão o idiota do } \\
\text { vilarejo, sobrinho do } \\
\text { ferreiro... }\end{array}$ & $\begin{array}{l}\text {...porque o fiel } \\
\text { matinal era ninguém } \\
\text { menos que o idiota da } \\
\text { aldeia, um sobrinho } \\
\text { do ferreiro... }\end{array}$ \\
\hline
\end{tabular}

Fonte: Elaborado pelas autoras

Vale a pena ressaltar a conotação bastante específica de 'ímpios', que, ao contrário de 'infiéis', refere-se àqueles conhecidos não só pela ausência da fé, mas, principalmente, pela falta de moralidade. Pode-se dizer, neste caso, que os tradutores em "A Marreta de Deus" "carregam nas tintas" e marcam de forma mais incisiva a fala do personagem, Padre Wilfred Bohun.

\section{Clergymen}

Vale a pena destacar também a tradução dada a 'clergymen'. Em “A Marreta de Deus” optou-se por 'clérigos', tradução literal do original e característica do campo semântico religioso. A ocorrência do termo é neutralizada, no entanto, em "O Martelo de Deus”, por conta da opção pela palavra mais genérica, e já bastante presente ao longo de todo o texto, 'padres'.

\section{6. À guisa de conclusão}

A partir da utilização de conceitos dos ETBC foi possível fazer uma comparação de aspectos detalhados de duas traduções de "The Hammer of God ": "O Martelo de Deus" (2006) e "A Marreta de Deus" (2011) quanto à apropriação do universo religioso presente no conto.

Os resultados gerados pelo exame dos corpora compilados para o presente trabalho comprovam a adequação da Linguística de Corpus para a análise de traduções literárias. No caso das duas 
traduções versus texto original do conto The Hammer of God, foi possível verificar que ambos os textos traduzidos apresentavam características em comum, em especial uma maior valorização do caráter místico-religioso presente no texto de Gilbert K. Chesterton, havendo, nos dois casos, ênfase desse aspecto em relação ao que se observa no original.

A partir da comparação entre os textos, em especial, de um grupo específico de vocábulos, observou-se que "A Marreta de Deus”, do grupo de tradução de Beatriz Viégas-Faria (2011), é o texto que recria o campo semântico da religião em tons mais acentuados e com maior riqueza de detalhes. Tal conclusão baseiase não somente no número de ocorrências de palavras traduzidas, mas também em sua especificidade e variedade. Ao contrário, "O Martelo de Deus", tradução de Carlos Nougué, parece ser um texto mais conservador e menos ousado na exploração do campo semântico da religião.

A comparação entre os textos escolhidos e o original do conto sem dúvida encerra diversas possibilidades de investigação científica. Assim, uma análise que leve em conta o cruzamento de outros dados certamente poderia ajudar a elucidar questões adicionais e revelar aspectos até então não observados sobre a tradução e sobre o estilo de cada tradutor. Do ponto de vista acadêmico, o valor do presente estudo está no próprio esmiuçar técnico de um produto literário e de suas formas traduzidas. Para os leitores e admiradores de Chesterton, no entanto, o valor dessa investigação ultrapassa o caráter técnico: consiste na possibilidade de revisitar a literatura chestertoniana por perspectivas diversas, sempre novas, e expressas aqui por meio do olhar de cada tradutor. 


\section{Referências}

American Chesterton Society. Disponível em: http://www.chesterton.org.

Baker, M. "Corpora in translation studies: an overview and some suggestions for future research". Target 7.2 (1995): 223-243.

Baker, M. "Corpus-Based Translation Studies: the challenges that lie ahead". In: Somers, H. (Ed.). Terminology, LSP and Translation Studies in Language Engineering, in honour of Juan C. Sager. Amsterdam/Philadelphia: John Benjamins, p. 175-186, 1996.

Baker, M. "Towards a methodology for investigating the style of a literary translator”. Target 12.2 (2000): 241-266.

Berber Sardinha, T. Pesquisa em Linguística de Corpus com Wordsmith Tools. Campinas: Mercado de Letras, 2009.

Camargo, D. C. Metodologia de pesquisa em tradução e lingüística de corpus. São Paulo; São José do Rio Preto: Cultura Acadêmica; Laboratório Editorial do IBILCE; UNESP, 2007.

Chesterton, G. K. (A). "O Martelo de Deus". In: A Inocência do Padre Brown. Rio de Janeiro: Sétimo Selo, 2006. p. 213-233.

Chesterton, G. K. (B). “A Marreta de Deus”. In: A Inocência do Padre Brown. Rio de Janeiro: LPM, 2011. p. $104-115$.

Chesterton, G. K. (C). "The Hammer of God." In: The Innocence of Father Brown. London: Penguin Books Limited, 2014. p. 116-138.

Garcia, L. A. Análise descritiva de duas traduções brasileiras do conto "The Invisible Man” de G. K. Chesterton. 2012. 267 f. Dissertação (Mestrado em Estudos da Tradução) - Centro de Comunicação e Expressão, Universidade Federal de Santa Catarina, 2012. Disponível em: https://repositorio.ufsc.br/xmlui/ bitstream/handle/123456789/100431/309790. pdf? sequence $=1$ \&isAllowed $=\mathrm{y}$. 
Kader, C. C. C.; Richter, M. G. "Linguística de Corpus: possibilidades e avanços." Instrumento (Juiz de Fora) 15.1 (2013): 13-23. Disponível em: https://periodicos. ufjf.br/index.php/revistainstrumento/article/view/18855.

Tagnin, S. E. O. Corpora: o que são e para quê servem. Minicurso. São Paulo, 2004. Disponível em: http://comet.fflch.usp.br/sites/comet.fflch.usp.br/files/ u30/Lexicografia_2004.pdf.

Zyngier, S., Viana, V., Silveira, N. G. "Discurso literário e linguística de corpus: uma visão empírica." Cadernos de Letras (UFRJ) n.28 - jul. (2011): 99-107. Disponível em: http://www.letras.ufrj.br/anglo_germanicas/cadernos/ numeros/072011/textos/cl2831072011zyngier.pdf.

Recebido em: 14/03/2019

Aceito em: 28/07/2019

Publicado em: Setembro de 2019

Aline Milani Romeiro Pereira. E-mail alinemrp@gmail.com ORCID: https://orcid.org/0000-0002-3192-2556

Diva Cardoso de Camargo. E-mail: divaccamargo@gmail.com ORCID: https://orcid.org/0000-0001-6924-4757 